\title{
MULHERES DE CERA, ARGILA E ARUMÃ: PRINCÍPIOS CRIATIVOS E FABRICAÇÃO MATERIAL ENTRE OS WAYANA
}

Lúcia Hussak van Velthem

O que há em comum entre um cavalo de pau e uma serpente de fibras? ${ }^{1}$ Segundo o historiador de arte Ernst Gombrich (1999), o cavalinho de pau é bastante trivial e geralmente se contenta em ocupar seu lugar no canto do quarto de uma criança sem nutrir ambições estéticas. Detesta afetações e assim se mostra satisfeito com seu corpo de madeira e sua cabeça talhada toscamente. A serpente de fibra é igualmente corriqueira, podendo ser encontrada em todas as cozinhas dos índios Wayana, quer seja tencionada entre dois travessões ou suspensa a um canto, fazendo crer que dormita. Tecida a partir de talas de arumã com casca, apresenta um lustroso e avermelhado corpo cilíndrico. Pretensiosa, aspira a píncaros estéticos, objetivo que alcança plenamente. Nas lides cotidianas, este utensílio presta-se a uma única função: espremer a massa de mandioca ralada, para o que foi justamente confeccionado. Na perspectiva indígena, estes dois atributos, especificidade de uso e propriedade funcional, sobretudo quando conjugados, constituem a condição máxima de valorização e beleza de um artefato.

Como podem ser descritos? Seria tão somente a "imagem" de um cavalo e a de uma serpente? Gombrich, no mesmo artigo, assinala que o brinquedo não apresenta a forma exterior de um cavalo, assim como, sob certo aspecto, o tipiti $^{2}$ não corresponde fielmente à figura de uma determinada serpente, pois lhe faltam as extremidades, a cabeça e a cauda. O historiador austríaco propõe que uma outra palavra talvez se revele mais apropriada para a questão. Trata-se de representação, a qual evocaria uma qualidade, a substituição. Em outros termos, tratar-se-iam de imagens que representam porque substituem. O cavalinho de pau logra ser um substituto para o cavalo porque ocupa o seu lugar, o que é passível de ser cavalgado torna-se de alguma forma um cavalo. Da mesma maneira, o tipiti constitui uma serpente porque o que é constringente reproduz o comportamento das serpentes constritoras, ${ }^{3}$ tornando-se uma delas. Cavalo e serpente possuem, nesse sentido - e como enfatiza o citado historiador aquela exigência mínima para o desempenho da função representacional. 
Esse caráter, contudo, deve ser esmiuçado, pois precisamos nos familiarizar com a ideia de que a representação não constitui uma ocorrência unívoca. Ainda segundo Gombrich, é necessário que se adquiram condições de aprimoramento de um conceito que se revela totalmente indispensável, a saber, o de "imagem conceitual", no qual o elemento representado está mais particularmente relacionado com o conhecimento que se tem a seu respeito do que com sua visualização mesma. Consequentemente, o brinquedo possui os elementos que remetem à ideia de "cavalidade", assim como o tipiti contém as ideias acerca da predação e referentes a certa "serpentinidade". Seria então totalmente correto dizer que o cavalinho de pau é constituído dos traços que formam o conceito de um cavalo? O historiador mencionado afirma que não, porque o cavalinho não é composto da mesma matéria dos cavalos, o que não ocorre com o tipiti, pois este é feito com a matéria, o arumã, de que determinadas serpentes são constituídas, permitindo reproduzir seus movimentos e os padrões de suas pinturas corporais.

A feitura de imagens está prenhe de perigos, adverte-nos Gombrich, pois devemos contar com a possibilidade de um "estilo" ser um conjunto de convenções nascidas de tensões complexas, o que é invariavelmente refletido nas criações que o adotam. Desta forma, destaca o historiador, num determinado estágio e para certos fins o cavalinho de pau, que reflete a imagem de memória de outros cavalos, necessita ter olhos, pois de que outro modo poderia ser cavalgado? Paralelamente, o tipiti, para incorporar a identidade de uma serpente sobrenatural específica, denominada kutupxi, e assim melhor espremer a massa de mandioca, deve apresentar a sua "decoração" corporal, aliás, a estrutura epitelial, ${ }^{4}$ elementos estes que se confundem na serpente e no trançado de arumã.

Segundo Gombrich, é preciso ainda considerar que a imagem feita pelo homem deve ser completa, mas não precisa tornar-se um duplo nas mãos do artista, pois se o cavalinho de pau exigir bastante aparência de vida, poderá galopar por conta própria! Da mesma forma, se o tipiti reunir em si a estrutura epitelial e o corpo completo de kutupxi, poderá ultrapassar a estreita faixa que separa o inanimado do animado e, então, serpente revivida, se recusará a engolir e a espremer a massa de mandioca e passará a deglutir os próprios Wayana!

\section{Ecos da serpente de fibras}

A fabricação material constitui uma atividade repleta de significados para os povos amazônicos, ${ }^{5}$ porquanto as habilidades técnicas representam 
uma questão de conhecimento, que associa diferentes formas de aquisição e produção que conjugam a visão e o gesto e muitos outros fatores (Gow 1999a:244). Considerando estes aspectos, o texto introdutório procurou destacar princípios criativos e produtivos, contrapondo a análise de Gombrich acerca de um modesto brinquedo ocidental às formulações dos Wayana a respeito de um artefato trançado, essencialmente utilitário, quando restrito ao processamento da mandioca. ${ }^{6}$ Este artefato provoca, como alguns outros produtos materiais wayana, um importante movimento de "imersão do cotidiano na ordem cosmológica" (Overing 1999:85) em um plano em que são requeridas habilidades do fazer. Essas habilidades são consideradas pelos Wayana como fundamentais para a completude social do indivíduo e a harmonia da vida comunitária, logrando efetivar mudanças do estado de uma pessoa. O aprendizado técnico, iniciado na infância, amplia-se e aprofunda-se com a puberdade porque visa ao casamento e à geração de filhos, para que se adquiram na velhice refinamento e especialização.

Para o jovem wayana o aprendizado para a confecção do tipiti é lento; trata-se de um objeto difícil de ser realizado - há o corpo a ser tecido e duas complexas formas de arremate. $O$ trançado deve principiar pelo centro do artefato, para que as entranhas (ietepú) da serpente, da qual o tipiti é a imagem conceitual, possam ser confeccionadas com esmero. Se as tiras de arumã não forem colocadas de forma correta, o artefato resultará desproporcional, e se não forem muito bem ajustadas, o trançado ficará frouxo e deixará vazar a massa de mandioca ralada. Num e noutro caso o movimento constritor, requerido do tipiti, fica comprometido. Tecer um tipiti é reproduzir e paralelamente dominar um elemento presente na cozinha de um sapo/demiurgo, Pëlë, ${ }^{7}$ que o utilizava enquanto objeto e o acondicionava enquanto cobra sucuriju. O domínio da confecção deste artefato indica que o rapaz está apto a casar. Na realidade, essa habilidade representa entre os Wayana a condição necessária ao matrimônio. Os jovens que desejam prolongar a despreocupada vida de solteiro retardam, portanto, o aprendizado desta manufatura. Tal opção tem se acentuado, e recentemente muitos jovens se casam sem estarem aptos a confeccionar um tipiti, fato que é considerado reprovável, porque esta carência é considerada o paradigma das uniões desajustadas.

A via de compreensão dos princípios criativos entre os Wayana engloba tanto a produção de filhos como a de alimentos e a de bens materiais. As limitações do presente artigo impõem que o foco principal privilegie as criações relacionadas aos artefatos de uso cotidiano e ritual. Contudo, serão abordadas questões que extrapolam as dimensões estritamente conectadas com os objetos para incorporar uma noção mais ampla de fabricação material, 
e assim encontrar ressonância nas inspiradoras abordagens de Gombrich (1999) Overing $(1991,1999,2006)$ e de outros autores. No presente trabalho, apoio-me largamente em meus anteriores escritos sobre o tema.

Os Wayana constituem um povo indígena que pertence à família linguística carib. A autodenominação corresponde a "eu (sou) gente", a saber, wayana. Em diferentes publicações anglo-germânicas são referidos como Aiana, Ojana, Waiano, porém, os textos de viajantes franceses que percorreram o interior da Guiana Francesa do século XVIII até princípios do XX referem-se aos Ouayanes, Orokoyennes, Roucouyennes, ao passo que os relatos em língua portuguesa os identificam, até meados do século XX, como Rucuianas, Uruguiana, Urukuyana (Gallois 1986; Velthem 1998). Segundo a tradição oral, os Wayana absorveram indivíduos originários de grupos indígenas de fala carib, como os Kukui, os Opagwana, os Upului, os Pupuriyana, os Arakapai, os Aparai, contra os quais fizeram incursões guerreiras no passado. Esses povos, assim como os Wayana, ocupavam diferentes bacias hidrográficas que banham uma extensa região compreendida pelo Brasil e países limítrofes da região guianense. No presente, e no Brasil, as aldeias wayana estão estabelecidas no extremo norte do estado do Pará, às margens do rio Paru de Leste, a área habitada inserida na Terra Indígena Parque Tumucumaque e na Terra Indígena Paru d'Este.

O caráter fluido das unidades sociológicas e o princípio segundo o qual a "mistura" é essencial para a vida social nas Guianas (Gallois 2005:12) ensejou, através de arranjos matrimoniais operados desde o século XIX, um movimento de fusão entre os Wayana e os Aparai, uma vez que compartilham, há longo tempo, a bacia dos rios Paru de Leste e Jari. Desta forma, a composição populacional das aldeias da região comporta geralmente indivíduos das duas etnias; algumas com discreta predominância dos Wayana e outras, dos Aparai. Devido a esse processo, são amiudadamente referidos, sobretudo pelos organismos governamentais, por um termo composto, Wayana-Aparai, mas esta expressão não é empregada corriqueiramente, enquanto meio de identificação individual. Prevalecem, na atualidade, múltiplas designações, nos casos dos descendentes de casamentos entre esses dois povos indígenas. Algumas privilegiam a ascendência paterna e, outras, a materna, o que permitiria supor certa flexibilidade das normas de descendência. ${ }^{8}$

Uma estada mais demorada entre os Wayana e os Aparai revela que, além da diferença linguística e identitária, esses povos se opõem de outras maneiras, muito embora possam ser considerados, globalmente, como pertencentes a um sistema social relativamente homogêneo ${ }^{9}$ percepção esta avalizada pelos próprios Wayana e Aparai. Uma das diferenciações estabelecidas, por uns e outros, apóia-se na constatação de que as representações 
e as exegeses sobre a produção artística são diversas, aspecto que é referido na narrativa mítica. Durante o combate travado para aniquilar Tuluperê, um sobrenatural, ${ }^{10}$ os Wayana viram/copiaram os padrões que estavam dispostos nos seus dois flancos, o que lhes permitiu a obtenção de um vasto elenco de padrões gráficos, característica que é reconhecida pelos Aparai. Estes, por sua vez, dominam com precisão as técnicas de manufatura, o que também é atestado pelos Wayana.

Os Aparai, muito embora não tenham participado da refrega, viram/ copiaram os padrões de apenas um dos flancos do sobrenatural, porém vagarosamente, uma vez que este jazia morto (Velthem 1998). O que está em jogo é uma determinada simultaneidade, uma vez que os Wayana e os Aparai capturaram, ao mesmo tempo, as técnicas de reproduzir os padrões e a de confeccionar trançados, por se tratar da categoria artesanal que permite reproduzir a totalidade do repertório das pinturas corporais do sobrenatural. Esta concepção permite o equilíbrio quanto à estética das respectivas fabricações dos Wayana e dos Aparai e enfatiza o valor atribuído à simultaneidade do fazer e "decorar".

A confecção de trançados e de outros artefatos específicos constitui uma atividade pública e, assim, a intenção do artista wayana é quase sempre evidente, cabendo-lhe, contudo, definir a identidade de sua obra. Como as partes do corpo humano que não podem ser descritas sem pronome possessivo, as coisas, feitas por esse mesmo corpo, enquadram-se nessa perspectiva. O vocábulo ëtiparé, "meus feitos", circunscreve a totalidade do que é produzido através do trabalho manual individual, masculino ou feminino, segundo princípios que são eminentemente wayana. Os Wayana produzem não apenas canoas, cestos e vasilhas, adornos corporais, máscaras e outros artefatos, mas também melodia vocal e instrumental, aldeias e casas, roçados, beijus de mandioca, bebidas fermentadas, frutas comestíveis e os demais vegetais cultivados e, ainda, os peixes que foram pescados, os animais capturados e os inimigos que foram trucidados. $\mathrm{O}$ conhecimento que permite produzir artefatos e muitas outras coisas é referido como tuwaré, "saber/conhecer". Um cesteiro habilidoso é um wama tuwaron, e um bom caçador é um tehamô waron, pois sabe fazer carne comestível. O saber humano representa o resultado de uma transmissão social, sexualmente diferenciada, cuja base pedagógica é a visualização de um modelo e o contínuo exercício de tentativa e erro.

A visão é o sentido que fornece a chave para a compreensão das concepções relacionadas ao saber, porque representa o principal meio, porém não o único, da aquisição de conhecimentos, um aspecto compartilhado com outros povos amazônicos (Gow 1988, 1999a; Overing 2006). A sede do 
conhecimento são os olhos, que abrigam um dos componentes da pessoa, o wayanaman, "como gente", porque indica as figuras invertidas que se apresentam nas pupilas. Estas figuras representam os verdadeiros detentores dos conhecimentos e das habilidades de um indivíduo, intermediando os processos propriamente gestuais que vão resultar na concretização dos artefatos. Entre a visão e o gesto há um contínuo intercâmbio e assim os olhos guiam as mãos, as quais asseguram, por sua vez, que os conhecimentos não se esvaiam. Desta maneira, um cesteiro passa os dedos nas linhas de um padrão recém-confeccionado para reter a sua conformação.

A manutenção dos conhecimentos está diretamente relacionada à proteção das figuras das pupilas, que não devem ser expostas a perigos. Os Wayana evitam trabalhar à noite, em execuções que forcem a visão, pois a perda da acuidade visual indica justamente o ataque de forças predatórias, associadas a um pequeno roedor. Os "moradores dos olhos" também não devem ser requisitados para produções impróprias, o que ocorre quando um homem busca executar uma manufatura feminina ou, o contrário, quando uma mulher se lança na confecção de um cesto. Resulta então um desregramento da relação visão/gesto, acelerando o envelhecimento do indivíduo.

O conhecimento/visão não representa apenas o sentido captado pelos olhos, por meio dos quais se percebe a realidade, mas também a compreensão das prescrições sociais impostas aos Wayana. Esses interditos não se referem unicamente aos procedimentos manufatureiros, mas dizem igualmente respeito ao seu uso adequado na vida cotidiana ou na atividade ritual e às diferenciações individuais, sexuais e etárias que são estabelecidas por seu intermédio. $\mathrm{O}$ fato de portar adornos rituais no dia-a-dia compreende uma transgressão que pode vir a ter um efeito radical, como relata o mito em que o jovem Iênumü, ao cingir uma coroa emplumada, torna-se cego e incapaz de executar qualquer artefato. Uma infração leve, como usar muitos atavios de miçangas no cotidiano, atrai apenas comentários maledicentes para o velho que deseja granjear a atenção feminina.

O indivíduo que possui todas as habilidades tecnológicas próprias ao seu gênero e à sua idade deve ser referido em certas circunstâncias como etihéwaré, porque ele "faz o conhecimento". Consistindo no mais alto grau da hierarquia do saber, as pessoas que detêm este título representam um ideal a ser seguido e são consultadas constantemente para diferentes assuntos da vida cotidiana e ritual. Entre os Wayana, a maestria artesanal é invariavelmente acompanhada de um profundo conhecimento das práticas rituais e das narrativas míticas, uma vez que abrangem domínios intimamente associados. 


\section{As três mulheres primordiais}

As narrativas míticas, conectadas a uma profunda imersão na ordem cosmológica, constituem-se em elementos fundamentais de compreensão da materialidade. Como observou Guss (1990:93) os mitos, ao serem associados aos artefatos, funcionam como um subtexto a essas produções, fornecendo elementos de entendimento da estrutura interna da expressão artística e criativa, aproximando-se assim de uma exegese nativa acerca das mesmas. Neste quadro referencial, artefatos e padrões atuariam como "imagens conceituais" (Gombrich 1999:8) e expressariam desta forma uma realidade diversa, relativa a outros tempos e domínios referidos nas narrativas míticas. Certos elementos constitutivos do cosmos wayana adquirem então a visibilidade requerida para a sua interpretação. O elemento basilar é composto pela tecnologia de produção pois, enquanto elemento fundamental da criação, permite efetivar a transposição daquilo que é do domínio da oralidade para o da materialidade, e igualmente expandir as suas dimensões.

Os mitos são designados na língua wayana pela expressão uhpakatonon ëtutóponpe, que significa "a fala original dos tempos primevos", e são compreendidos como pertencentes aos demiurgos, os kuyulitom, e não aos Wayana, que apenas os reproduziriam. Desta forma, podem ser especificados pelo nome próprio dos criadores dos tempos primevos como Umalé etutóponpë, "a fala de Umalé", o que permite enfatizar uma característica de discurso individualizado, dotado de autoria (Velthem 2003). Enquanto discurso dos demiurgos, os mitos contêm um aspecto relevante, que é o seu caráter instrutivo, conectado à transmissão de prescrições que refletem um modo de ser e de produzir que são próprios a esses seres.

Um dos mais importantes mitos para a compreensão destes aspectos é o que faz referência à gênese do mundo wayana, descrevendo os eventos desses tempos e detalhando a tecnologia criativa dos demiurgos e a forma como era exercida. Neste mito, a criação destacada diz respeito à arte de produzir mulheres a partir de matérias-primas diversificadas. Resumidamente, a primeira parte do mito descreve como um demiurgo, referido como Tenä ou Umalé segundo as diferentes versões, ${ }_{1}^{11}$ sentindo-se só, resolve criar uma mulher destinada a ser sua irmã e a produzir alimentos, principiando assim a cadeia das trocas matrimoniais e dos atos criativos.

A fala de kuyuli ${ }^{12}$ (Fragmento mítico, extraído da narrativa de Aimore Wayana, transcrita em Velthem 2003:397-409):

Quando não tinha tudo, não tinha água, não tinha terra, não tinha o pau. Ele nasceu ele mesmo, Tëná. Ele nasceu sozinho, só ele, mesma coisa que kuyuli. 
Aí ele disse:

"Mas não tenho quem trabalha pra mim, eu vou fazer mulher."

Aí ele fez. Ele fez primeiro de cera de abelha, moropi. Outro dia, moça, mulherzinha, nome dela Moropi. Aí ele disse:

"Acordou? Olha tu vai trabalhar hoje, tu vai buscar mandioca pra fazer bebida pra mim". "Está aqui jamanchim, está aqui pau!"

Aí ela foi lá na roça. O sol esquentou ela, aí derreteu, morreu. Morreu mesmo, não aguentou no sol. Demorou, demorou não sei quanto tempo. Tëná se aborreceu:

"Mas que demora, cadê ela?"

Foi ver na roça, estava lá, morta. Ah! Não presta! Voltou. Qual é bom então pra fazer mulher? Ele estava imaginando, pensando. Experimentou barro, ëliwé, desse que gente faz panela. Aí fez. No outro dia estava bom. Bonita moça.

"Que tal, acordou? Vai trabalhar hoje, vai fazer bebida pra mim". "Está aí jamanchim, o pau, tu vai lá na roça!"

Ëliwé, nome dela, não levantou, pesada, pesa, não pode levantar. Ela queria levantar, mas não pode, porque barro pesa, por isso ela não levanta.

"Então tu não presta!"

Aí matou ela, tinha sangue dentro, matou ela mesmo. Aquela não é bom! Qual é bom então? Aí fez arumã, wama. Aí fez, outro dia tá viva, moça bonita.

"Como vai, acordou? Tu vai trabalhar hoje. Tu vai buscar bebida pra mim. Mandioca tu traz, eu tô ensinando. Esta aí pau pra cavar, está aí jamanchim."

Aí Arumana, nome dela foi na roça. Arrancou mandioca, trouxe. Ralou e fez pra sakurá, ${ }^{13}$ mas não está mastigado. Aí ela disse, outro dia:

"Está aqui bebida."

Tomou bebida, não está bom, Tëná não gostou.

"Mastigou?" — perguntou.

Não mastigou, não tinha dente, dente não tinha.

"Não está boa a bebida, tu fez ruim, não tá mastigada!". "Vamos ver, eu vou botar o teu dente".

$[\ldots]$

[Depois] pegou mundubi, aí botou dente dela .

Por isso que nosso dente não atura, moço ainda, logo tá caindo dente de nós.

Na geração das três mulheres, mulheres estas que, como os artefatos, são designadas de acordo com a matéria-prima de confecção, destaca-se que as primeiras são modeladas em cera e em argila. Embora tivessem vida, revelaram-se ineficazes no cumprimento da tarefa a elas atribuída devido à impropriedade de seus materiais constitutivos. A mulher de cera derreteuse ao sol, a outra, tão pesada, não se locomoveu. O demiurgo resolve então 
tecer uma terceira mulher com tiras de arumã e denomina-a justamente de Arumana ${ }^{14}$ Ao adquirir vida, revela-se ágil e capaz de realizar a tarefa imposta pelo criador, a qual é essencialmente feminina: colher e processar mandioca com o propósito de confeccionar bebidas fermentadas, o alimento dos demiurgos. As matérias-primas primordiais, sucessivamente empregadas pelo demiurgo - cera, argila e arumã - revelam também um sentido de escalonamento em elaboração/aprendizado técnico, primordial e atual. Para os demiurgos, consistia na busca da eficiência da obra criada; para os humanos, corresponde a domínios bem delimitados que opõem a infância à vida adulta e os homens às mulheres. A cera é modelada pelas crianças, meninos e meninas, em suas brincadeiras; a argila é usada pelas mulheres na confecção do vasilhame cerâmico, e o arumã é empregado pelos homens nos trabalhos de cestaria.

O mito relativo à gênese prossegue relatando como a mulher primordial, tendo engravidado pelas artes de outro demiurgo, parte à procura do pai de seus filhos. Depois de muitas peripécias, chega a uma encruzilhada e, ao tomar a direção errada, alcança a aldeia dos homens/onças. Ali encontra abrigo na casa de um sapo/demiurgo que não consegue evitar que Arumana seja devorada pelos felinos; entretanto, salva seus quatro filhos, adotando-os. A segunda parte do mito descreve as aventuras dos meninos gêmeos Pararimó e Waranaré em seus propósitos de vingança pela morte da mãe, culminando com o aniquilamento dos homens/onças, aprisionados em uma casa cerimonial na qual se tinham abrigado quando os gêmeos desencadearam as chuvas do dilúvio. Após a retração das águas, os gêmeos reencontram o sapo/demiurgo e retomam a vida terrestre. Numa pescaria, contudo, "fisgam" suas irmãs, metamorfoseadas em peixes e, por meio desse ato, cometem incesto. A conclusão do mito é a subida dos demiurgos ao céu e a sua transformação em constelações, pois este destino, como indica Schoepf (1987:137), permitiria o restabelecimento da ordem universal perturbada pelo incesto cometido.

O desenrolar do mito especifica que os atos criativos dos demiurgos não provinham de um aprendizado adquirido, mas sim de um saber intrínseco, o qual se exercia prontamente, adequando-se às necessidades eventuais. A sua característica principal era a de possuírem um componente de metamorfose, correspondendo a certo tipo de tecnologia que expressa a grande ebulição criativa dos tempos primevos. Para os Wayana, a metamorfose representa uma transformação radical, procedimento que é referido em sua língua como tanuktai, e cujo paradigma é a metamorfose da larva em borboleta. Este termo designa os processos metamórficos que são relatados nos mitos, como a transformação dos humanos em animais e a dos sobrenaturais em humanos 
e a sua correspondente volta à sobrenaturalidade, e ainda a metamorfose de entes inanimados em animados e a operação contrária. Todos esses feitos empalidecem, contudo, em face dos poderes de metamorfose da serpente/ larva Tuluperê. O surgimento dos artefatos, como são materializados nos dias atuais, representa sempre o resultado de um processo de metamorfose como aquele que ocorreu com Pïrau, "flecha", que era um intrépido guerreiro e que, ao perder a visão, se transformou na flecha que é utilizada pelos Wayana. A respeito da metamorfose, retoma-se a narrativa mítica:

Aí choveu, choveu, choveu. Fica água grande, cresceu água, alagou.

Tinha vovó, aquele sapo cururu, Pële. Tinha colher pra mexer panela, colher de pau.

"Me dá aqui tua boca, kuni" (avó)!"

"Não faça isso, menino!"

"Me dá aqui!"

Aí meteu [a colher] na boca dela. Aí tanuktai ficou como pato.

Por isso que não morreu.

Aí pegou pilão, aquele que nós soca. Botou, aí subiu, fica como [palmeira] miriti. Aí subiu pra cima os irmãos.

Aí alagou tudinho, morreu tudinho, alagou tudo.

Aí demorou, demorou não sei quantos dias, uma lua, parece.

Não aguentaram mais [os quatro irmãos]. Queria se espalhar, mas empurrou irmã. Escapuliu e tipum! Dentro d'água.

$[\ldots]$

Caiu Letikoni, caiu Murokoni, as duas.

Ficaram como peixe, como peixe ficaram.

Segundo o mito, as artes dos demiurgos permitem que um trançado se transforme em mulher, posteriormente em quelônio, e suas unhas, em flautas; que artefatos e casas minúsculas se agigantem, as quais se transmutam depois em rochedo. A tecnologia metamórfica exercia-se tanto sobre materiais naturais, como arumã, argila, cera e palhas, que acabavam de ser criados, como também sobre as excreções dos corpos dos próprios seres primordiais. Percebidas como matérias-primas, eram empregadas pelos demiurgos para criarem coisas, animais e alimentos, como o beiju, originário do pus das feridas de Omopará. As matérias-primas primevas possuíam ainda a peculiaridade de poderem ser, elas próprias, dotadas de agência metamórfica, como é o caso dos jazigos de argila que moldavam por si mesmos as panelas de cerâmica. As criações demiúrgicas são paradigmáticas, porque eram belas, eficazes e transmitiam vida às obras concluídas, que passavam a ser 
dotadas de agência. Ademais, essas criações empregavam uma tecnologia que se exercia a partir da associação simultânea e integrada dos elementos constitutivos: matéria-prima, forma e "decoração". Resultavam assim em obras com uma característica de inerência que não permite, por conseguinte, a modificação desses elementos, como pode ser observado nas serpentes sobrenaturais e nos cestos trançados.

O mito em questão fornece, portanto, princípios orientadores para determinadas criações dos Wayana, os quais são desenvolvidos segundo as criações dos demiurgos e encarados enquanto modelos a serem reproduzidos quando buscam certos efeitos que são fundamentais durante os rituais ou em circunstâncias cerimoniais. Nessas ocasiões, os humanos procuram comer, falar, andar, adornar-se, trabalhar da mesma forma que essas entidades primordiais. Com tal procedimento, desencadeiam processos generativos que reinstalam esses tempos no seio da aldeia. No cotidiano, entretanto, as criações dos Wayana visam a uma classe de efeitos diferentes, porque devem assegurar a reprodução social e uma vida comunitária harmoniosa (Overing 1999). Portanto, a tecnologia desses momentos precisa ser contrária à dos tempos rituais e, assim, acaba por inviabilizar as características fundamentais das criações dos demiurgos, submetendo-as à condição humana.

A tecnologia dos demiurgos constitui um ideal e é, em paralelo, um grande perigo, pois é poderosamente generativa. Necessita ser controlada e dominada, como observado por Overing (2006:33) para os Piaroa, que têm que purgar os agentes tóxicos e poderosos contidos em tudo o que detém poder transformador. Para os Wayana, e no âmbito restrito da produção de objetos, uma das principais formas de controle é agir sobre as matérias-primas de maneira eminentemente humana e social. Isto significa trabalhar pausadamente, nas horas propícias, pela manhã e ao entardecer, à vista de todos, tanto no espaço doméstico como na roda masculina do centro da aldeia. A condição da tecnologia humana requer igualmente a variabilidade, o que representa, para um homem, concluir hoje um cesto e amanhã se dedicar ao entalhe de um remo ou a qualquer outra atividade. Assim, a tecnologia humana não comporta um desregramento por excesso, como produzir incessantemente o mesmo tipo de artefato. Um comportamento obsessivo, tarentekê, acarreta a própria forma de agir dos demiurgos, provocando o surgimento da desordem por excelência que é a doença, afetando tanto o artesão como seus parentes próximos. A reprodução da vida cotidiana admite apenas uma tecnologia humanizada e, portanto, variada e comedida.

Nos rituais, contudo, o câmbio tecnológico é imprescindível, porque muitas das complexas ações generativas desses momentos visam, em última análise, ao surgimento da agência metamórfica, da tecnologia dos seres 
de outros tempos e espaços. Para promover a sua irrupção, é necessária a ativa participação dos Wayana na geração de procedimentos específicos, os quais os levam a abandonar as técnicas humanas e a adotar as demiúrgicas. Os objetos de uso cerimonial e ritual, como as máscaras, devem ser detalhistas e, portanto, requerem uma vasta e especializada fabricação. As máscaras, em sua performance, apresentam componentes não-visuais, como movimentos, sons e fragrâncias, que são significativos meios generativos de outras dimensões. A experimentação criativa revela-se assim tão profunda que desencadeia o processo de metamorfose, e as máscaras transformam-se então em seus modelos, trazendo a si mesmas e a sua realidade para o seio da sociedade wayana. Esses artefatos são, desta forma, transformadores, porque atuam sobre a realidade espaço-temporal e, consequentemente, sobre os humanos (Velthem 2000a). Tais procedimentos representam a possibilidade de que os Wayana dispõem para conferir "alento" aos objetos, fazendo com que os mesmos possam cumprir o seu papel de agentes de transformação sobre os membros da sociedade.

A adoção da tecnologia dos demiurgos ocorre, entre outros momentos, especialmente durante as fases preparatórias dos rituais iniciáticos. Para este propósito, os jovens reúnem-se durante vários dias, do raiar ao pôr-do-sol, para tecer sem descanso um tipo de cesto cargueiro, wakalaimë, de trama muito cerrada, usado no transporte da massa de mandioca, necessária para o preparo de bebidas fermentadas. O excessivo labor dos jovens associa-os à efervescência produtiva dos tempos primevos, quando jovens/onças fabricavam ininterruptamente esses cestos, na sequência do mito que nos ocupa. A aquisição da capacidade de agir como esses seres míticos é um requisito fundamental para que o jovem consiga suportar, na fase culminante do ritual, as picadas de formigas ou de vespas venenosas inseridas em uma placa vesicatória e aplicadas ao corpo, tórax e membros. As formigas conferem saúde e capacidade reprodutiva ao jovem, as vespas, as habilidades requeridas para o manejo do arco e flecha, com os quais exercerá atividades predatórias, uma prática em tudo similar à dos Piaroa (Overing 2006:45). A imposição do vesicatório constitui a mais profunda das intervenções que a sociedade wayana exerce sobre um indivíduo, acarretando a retirada simbólica da pele do jovem, propiciando uma "mudança de estado" (Chaumeil 2005), transformando-o em um homem adulto capaz de realizar atos criativos e procriadores.

Outra forma de geração de tecnologia demiúrgica está conectada a um intento valorativo que, ao incidir sobre um artefato, propicia-lhe incremento estético, desígnio que se fundamenta e se veicula através da matéria-prima e de outros atributos dos artefatos. Segundo este princípio, uma coroa radial, 
pumari, para se tornar particularmente estimada, deve ser confeccionada com plumas amarelas de um tucano que tenha as pontas avermelhadas e, por esse motivo, são referidas como "ensanguentadas". A valorização que impregna a coroa é resultante do fato de o plumista wayana empregar uma matéria-prima que estabelece paralelismo com a que foi utilizada pelos demiurgos. Estes, no exato momento em que os pássaros, de cores indistintas, banhavam-se no sangue do muçum/arco-íris Walamúimë para adquirir belas cores, retiraram plumas de um tucano ainda coberto de sangue para confeccionar seus ornamentos. Neste caso, a efetivação da valoração estética requer a expansão das dimensões espaciais e temporais dos materiais empregados visando equipará-los, o mais fielmente possível, aos materiais empregados nos tempos primevos. Outras valorizações, não menos importantes, estão conectadas a uma matéria-prima de origem vegetal, o arumã.

\section{O arumã e as peles pintadas}

A valorização estética de um artefato é extremamente apreciada, mas a sua utilidade e eficácia não ficam em segundo plano, porque estes atributos constituem o objetivo primeiro de toda e qualquer criação. O arumã atesta, desde os primórdios, a adequação deste material para a criação de obras que produzem efeitos desejados: mulheres que preparam alimentos e geram filhos, artefatos apropriados para a elaboração de comidas e bebidas derivadas da mandioca brava. Entre os Wayana, o preparo e o consumo de bebidas fermentadas extrapolam o quadro familiar, transformando-se em um domínio culinário autônomo que adquire relevância em rituais por serem na realidade o alimento dos demiurgos. Referidas genericamente como okê, "cachiri", essas bebidas integram o quadro de recriação dos tempos primevos por ocasião dos rituais e, em consequência deste fato, devem ser ingeridas em excessivas quantidades. Esta prática provoca a sua frequente regurgitação pelos participantes, agregando a este ato, muito provavelmente, um objetivo purificador, como sugere Chaumeil (2005:173), complementando assim a purificação obtida pelos efeitos lacrimogêneos da pimenta torrada, prática que integra todos os rituais wayana.

A tecnologia da cestaria revela uma outra qualidade do arumã que é determinante para a sua valorização nos tempos primevos e no presente. Trata-se da possibilidade de execução de ações simultâneas, quer no próprio ato de trançar, quer nos efeitos obtidos. A cestaria constitui uma modalidade artesanal designada como tikaphé, pois emprega as duas mãos em movimentos similares e simultâneos, ao contrário da produção dos entalhes 
em madeira em que apenas uma das mãos trabalha. A simultaneidade dos efeitos revela-se particularmente nos tecidos de fibras vegetais: arumã, cipó, algodão ${ }^{15}$ e nos de miçangas, pois os artefatos produzidos não apresentam independência entre o seu aspecto formal e o sentido "decorativo" que ostentam. Na cestaria isto significa que as tiras de arumã, ao serem entrançadas, possibilitam ao mesmo tempo a produção de um trançado e de um ou mais padrões, os quais se materializam sob formas diferentes, com resultados estéticos igualmente diversos. Esta técnica está mais estreitamente conectada às produções demiúrgicas, ao contrário de outras técnicas, como a cerâmica, que requerem etapas sucessivas para a sua realização: primeiramente, a coleta e o processamento dos materiais constitutivos; em seguida, a elaboração formal; posteriormente, a queima e a pintura dos motivos gráficos; e, por último, o envernizamento de base vegetal.

A apreensão da simultaneidade da tecnologia cesteira exige a conexão a um complexo simbolismo relativo ao arumã. As hastes deste vegetal são compreendidas como dotadas de um revestimento em tudo similar a uma pele (humana, animal, sobrenatural): a película externa corresponde, portanto, à epiderme e a interna, à derme. Esta peculiaridade permite ao arumã, ao ser entrançado, a produção de "peles". As "peles" podem ter duas características distintas, segundo o processamento técnico conferido às hastes de arumã. As hastes que não são raspadas ao serem empregadas mantêm a película externa, e assim produzem trançados que ostentam uma cor unida, avermelhada. As hastes cuja película externa é raspada, aliás, "esfolada", permitem a aplicação de tintura, e resultam em trançados que apresentam, portanto, padrões contrastados em claro-escuro. A primeira das técnicas foi empregada pelo demiurgo que criou/entrançou uma mulher, Arumana, de pintura corporal uniforme. A segunda é específica de seres sobrenaturais e, sobretudo, de Tuluperê, cujas pinturas corporais são grafismos em claro-escuro que foram vistos/copiados pelos Wayana, com a característica de serem entrançados, como mencionado.

Os mitos, por meio da ênfase atribuída ao arumã, ressaltam a dupla peculiaridade da pintura corporal, uniforme ou com padrões, dos componentes cosmológicos. Apontam ainda para o caráter antagônico dessas pinturas e a possibilidade de sua alternância, um privilégio restrito aos seres humanos e que referenda efetivamente a sua humanidade. O ponto a ser destacado é que no mito sobre a gênese, o demiurgo, ao utilizar arumã proveniente da camada externa, determinou que a primeira mulher eficaz fosse especificamente pintada com urucu. ${ }^{16}$ Os artefatos trançados de arumã, dotados da película externa, adquirem ao secar uma coloração vermelha acastanhada que é especificada como tamarê, termo que também identifica a tonalidade de uma pintura corporal de urucu sem frescor, pois não aplicada recente- 
mente. Esta coincidência indica que Arumana estava socializada, pois sua pele, untada com urucu envelhecido, denota uma pessoa que habitualmente se pinta e que, portanto, está de posse de suas prerrogativas sociais, uma característica dos adultos dotados das possibilidades procriadoras e dos conhecimentos requeridos para outras criações. A agência feminina, em última instância uma obra do demiurgo, requereu a colocação dos dentes e da língua em Arumana — como mencionado pelo relato mítico na sequência — permitindo que a primeira mulher se especializasse técnica e socialmente. Os dentes possibilitaram-lhe a mastigação, essencial na produção de bebidas fermentadas, e a língua, a comunicação por meio da fala.

Uma tecnologia caracterizada pela simultaneidade destaca um outro importante aspecto associado ao arumã, agora devido às suas conexões a uma outra categoria de seres, extremamente numerosa, que são os sobrenaturais. Estes são classificados pelos Wayana de acordo com o seu aspecto, que pode ser antropomorfo, serpentiforme ou de felino. Os membros desta categoria são reconhecidos por ostentarem belos padrões em suas peles, os quais são essencialmente "decorativos". Não se trata, no entanto, do sentido que o Ocidente confere à decoração, aspecto que constitui uma característica das artes indígenas amazônicas como discutido, entre outros, por Gow (1988, 1999a), Velthem (1992, 2000a, 2003), Lagrou (2007).

De um modo mais específico, os padrões, miriken, ${ }^{17}$ fazem referência às pinturas corporais de dois sobrenaturais paradigmáticos: Tuluperê, "serpente/larva de borboleta, e Maruanãimë, "serpente/raia". Esses padrões são compreendidos em conformidade com repertórios individualizados, inerentes e permanentes desses seres. Cada padrão, mirikut, integra por conseguinte um desses repertórios, mas expressa uma identidade formal e nominativa que o diferencia dos demais. Entretanto, configura um e ao mesmo tempo vários outros seres existentes em espaços e em domínios diferenciados, operando assim como uma espécie de recapitulação cosmológica.

Os padrões empregados pelos Wayana em várias categorias artesanais e na pintura corporal pertencem ao repertório de Tuluperê. Mais especificamente, o resultado do entrançamento das tiras de arumã constitui a reprodução de diferentes partes de sua pele pintada e não apenas de suas pinturas, como ocorre com outras categorias artesanais, como a cerâmica. A cestaria representa, por conseguinte, a categoria que detém o maior número de padrões/técnicas de trançado, pois reproduz a pele e as pinturas que recobrem todo o corpo do sobrenatural, e não apenas algumas partes, como ocorre com outras categorias artesanais.

Os padrões/técnicas de trançado evidenciam a própria estruturação sobre o corpo de Tulupere como sua pintura corporal. No rosto e no tronco 
da serpente/larva estão os motivos contrastados em claro-escuro, cada um dos quais constitui o mirikut, "padrão" propriamente dito. Outras partes do seu corpo apresentam motivos que não têm esta característica, pois não são contrastados. Nos membros estão os de trama cerrada, porém, sem pintura, mirikut anon pïrá, e na cauda são encontrados os padrões de trama vazada ou "padrão de olhos", mirikut ewú.

Os padrões contrastados estão diferentemente espalhados pelo tronco de Tuluperê. Os que estão contidos nos flancos só podem ser observados em uma única face. Entretanto, os que se apresentam no ventre são padrões de dupla face e podem ser apreciados dos dois lados. Indicam, por sua constituição e localização, que este ser tem as entranhas igualmente pintadas. "Apreciar" esses padrões significa que um indivíduo foi capturado e deglutido pelo sobrenatural e que o seu fim está próximo (Velthem 2000b). Os padrões de dupla face, mirikut amerë anon, são os que [mais] verdadeiramente representam Tuluperê, porque descrevem a sua fundamental característica comportamental: a predação. Esses motivos são dispostos em reduzido número de artefatos, um dos quais é o cesto cargueiro decorado, katari timiriké, aliás, a imagem conceitual do seu tronco. São apontados como os mais belos e intrincados padrões do elenco "decorativo" wayana e a sua reprodução é conseguida apenas por artistas muito habilidosos, aqueles que também, por meio desse exercício, mais profundamente exercem o poder de visualizar o mundo sobrenatural.

Entre os Wayana, os padrões constituem o resultado de uma experiência visual (Gow 1999a:237). A sua aquisição é o resultado da observação de uma estética que foi vista/copiada, nos tempos primevos, da pele de Tuluperê e, na atualidade, é percebida em muitos objetos, sobretudo nos trançados de arumã. Este aspecto é fundamental, porque tal experiência visual, pretérita e atual, indica que a estética wayana serve antes para "ver" do que para ser "vista". Para os Wayana, a possibilidade de perceber aspectos ocultos da visão ordinária concentra-se na descrição da morfologia e da pintura corporal de Tuluperê e de outros sobrenaturais, assim como das suas características predatórias e metamórficas. Esta constatação explica o caráter essencialmente representacional de cada padrão, pois individualmente configura uma determinada entidade, e paralelamente muitas outras a ela associadas morfologicamente. Ao final, todos os padrões se reúnem em uma configuração paradigmática: a pele pintada deste sobrenatural.

O elemento fundamental de tal conjunção representativa é que, em um padrão, estão contidas tanto a noção de desenho como a de imagem. Contudo, ao contrário do pensamento dos Piro (Gow 1988:27-28), para os Wayana o padrão não representa uma elaboração humana por sempre ser 
uma das pinturas corporais de Tuluperê, quer esteja em sua pele, ou em um artefato. A elaboração humana do padrão concentra-se nos processos de aplicação técnica, cujo paradigma é a pintura. Isto decorre do fato de que, no seio da sociedade, o padrão só existe enquanto imagem, ukuktop, uma vez que a sua concepção literal se manifesta exclusivamente em domínios cosmológicos diversos onde expressa um outro sentido estético.

\section{Os corpos íntegros e os desmembrados}

O sentido de imagem não se restringe à produção de padrões, mas todo e qualquer resultado da produção artesanal de homens e mulheres é referido como ukuktop, "imagem", que também significa "experimentar" e assim se alinha com a definição apresentada por Gow (1999b:302) a respeito da representação figurativa. Os artefatos constituem uma reprodução imitativa do efeito da atividade criativa exercida nos tempos primevos. São compreendidos enquanto cópias dos elementos existentes nesses tempos porque os substituem, porque tomam o lugar, no presente, daqueles seres e elementos do passado. Assim, a rede de dormir reproduz/constitui a teia da aranha primordial, um determinado banco masculino encarna uma ave de rapina, o urubu rei, e a peneira quadrangular tem exatamente o mesmo aspecto de um ninho de vespas venenosas.

A identidade que une as produções atuais às pretéritas é reforçada pela consideração da raiz do verbo ukuktop, que vem a ser ukuk, a qual faz referência às dimensões dos elementos concretos. Nesta acepção, um objeto se caracteriza como o resultado de um experimento que reproduz o volume e a estrutura de seres e elementos que tiveram seus parâmetros morfológicos estabelecidos nos tempos primordiais. Segundo esta perspectiva, os objetos materiais compõem efígies porque são representações plásticas, "retratos" dos seres primordiais ou daquilo que permite identificá-los, o que se confunde no pensamento teórico wayana. Essa origem em um tempo de fronteiras fluidas e o sentido de efígie, conectados a uma representação em vulto, permitem que os artefatos de uso cotidiano e ritual sejam compreendidos como corporificados. Dito de outra forma: esta acepção admite destacar que os artefatos constituem "corpos"18 providos de cabeças, membros, seios, troncos, genitais que revelam características antropomórficas, zoomórficas ou especificamente sobrenaturais, atestando desta forma a sua origem.

Os objetos, tanto os de uso cotidiano como os empregados em rituais, apresentam portanto as características formais de seus modelos, os quais eram dotados de agência nos tempos primordiais. Consequentemente, ao 
contrário do que afirma Gombrich (1999:1), para quem é totalmente irrelevante o fato de o cavalinho de pau apresentar ou não a forma exterior do modelo, para os Wayana é fundamental tal correspondência. A forma atual deve corresponder aos cânones estabelecidos pelos demiurgos, pois há nos atos criativos dos humanos uma necessidade de identificação com as criações dos tempos primordiais. Esta particularidade confere às criações wayana um eminente sentido icônico (Munn 1973; Pierce 1977) que revela a existência de algum elemento de semelhança entre a forma visual e seus significados, possibilitando o reconhecimento dos elementos representados.

Nos tempos atuais esses corpos podem apresentar-se de duas maneiras: parcelados ou íntegros. Os artefatos de uso cotidiano são concebidos como corpos transformados, pois já sofreram, conforme relatado em vários mitos, um processo que vem a ser justamente o seu desmembramento, ou a supressão das suas características originais, descontroladas e predatórias. Para a viabilidade das lides cotidianas, o parcelamento dos seres primevos se impõe, visto ser necessário que se transformem em coisas que possam ser utilizadas pelos humanos. Em outros termos, isto significa serem necessários a preponderância e o domínio dos humanos sobre a agência dos objetos. O parcelamento dos corpos/artefatos permite que as mulheres empreguem no processamento da mandioca uma peneira circular, e não uma serpente enrolada que, ao perder cabeça e cauda se metamorfoseou neste objeto; da mesma forma esse processo faculta a um homem sentar-se em um banco zoomorfo e não se alçar aos ares nas costas de um urubu-rei, uma vez que este, providencialmente, perdeu suas asas.

A agência dos objetos está diretamente relacionada com a sua corporalidade - o aspecto formal do artefato - e com a movimentação desse mesmo "corpo". O movimento referido corresponde à animação dos artefatos durante a sua utilização e corresponde a uma maior ou menor capacidade de reproduzir os movimentos peculiares que possuíam nos tempos primevos quando eram seres dotados de vida. Consequentemente, as panelas de cerâmica são, até o presente, pesadas e inertes, e o nosso conhecido tipiti ainda "encolhe e espicha" como a serpente/larva Kutupxi, mas muito mais vagarosamente. Este fato o/a impede de lançar-se aos galhos da árvore awaraimë, onde imitaria os macacos-coamba para atrair caçadores incautos, pois visa cortar-lhes as cabeças e devorá-los ruidosamente, cuspindo seus ossos à distância (Velthem 2003:248).

Como mencionado no início, os princípios criativos entre os Wayana são mais amplos do que os limites descritos, uma vez que compreendem igualmente um sentido que revela procedimentos apropriados à produção de filhos e a muitas outras coisas e ao estabelecimento de um propósito comunitário, 
vinculado a uma transmissão social. Desde os primórdios, o produto de uma fabricação está intimamente conectado com o indivíduo que é capaz de materializá-lo. A principal decorrência desta concepção é o reconhecimento dos objetos e dos padrões, assim como das tinturas, enquanto propriedade dos demiurgos e não propriamente dos Wayana. Como enfatizam, eles nada criaram, pois se julgam apenas os experimentadores das criações dos seres primordiais. O resultado de tais experimentos, a execução de obras segundo um modelo preestabelecido, constitui um ipokan ${ }_{1}^{19}$ e é assim considerado como apropriado ao uso dos Wayana, porque passou a deter uma característica marcadamente humana e opera, efetivamente, na construção dessa humanidade.

A significação das fabricações está conectada à ideia de uma contínua imitação e atualização dos modelos primordiais e se exerce enquanto criação construtiva, mas não arbitrária, envolvendo os demiurgos, os criadores por excelência e os próprios Wayana, seus fiéis executores. Nas aldeias, muitos artefatos observados nas últimas décadas do século XX estão em obsolescência. Os que são encontrados no presente refletem as mudanças efetivadas a partir do incremento do contato que incentivou o surgimento de novas percepções, assim como a presença de uma infinidade de objetos e materiais industriais.

Contudo, como a essência dos artefatos e a dos corpos é de contínua transformação, os objetos seguem como significativos arcabouços materiais/conceituais que proporcionam aos Wayana meios de adaptação a novas realidades. A constante renovação das formas trançadas mantém, entretanto, a coerência interna por intermédio da estética "decorativa", dos padrões, os quais não mudam, porque esta não é a sua função primordial. Originando-se da pele da serpente/larva sobrenatural, comungam com esta imutabilidade da decoração corporal. Em outros termos, no pensamento wayana, os artefatos constituem "recriações" e assim podem incorporar componentes humanos de mudança. O elenco "decorativo", por sua vez, ao configurar uma "transposição", permanece invariável em decorrência de uma natureza não-humana.

Recebido em 06 de maio de 2008

Aprovado em 24 de novembro de 2008

Lucia Hussak van Velthem é pesquisadora associada do Museu Paraense Emilio Goeldi, atualmente na SCUP/MCT. E-mail: <lhussak@mct.gov.br> 


\section{Notas}

${ }^{1}$ A fibra referida é o arumã, um caniço silvestre (Ishnosyphon sp), empregado por numerosos povos indígenas, sobretudo os do norte-amazônico, na confecção de trançados. Cf. Guss (1990) e Velthem (1998) para referências sobre cestaria dos povos de língua carib.

${ }^{2}$ Tipiti é um termo originário das línguas indígenas do tronco tupi e foi mencionado por Hans Staden em 1557. Este artefato é designado pelos Wayana como tumkëi, possui corpo cilíndrico, trançado com fibras de arumã e é usado para espremer e, assim, secar a massa de mandioca ralada. Cf. Carneiro (2000) para uma detalhada história da evolução do tipiti.

${ }^{3}$ Identificadas como aramari, "jibóia" (Boa sp) e okoiwuimë, "sucuriju" (Eunectes sp).

${ }^{4}$ A pele ventral de Kutupxi é denominada de tipapôman e a dorsal, karupiman. Estes termos identificam as duas técnicas de trançado extensíveis produzidas pelos Wayana e que são específicas, mas não exclusivas, dos tipitis.

${ }^{5}$ Este aspecto foi abordado por Guss (1990); Overing (1991, 1999); Velthem (1998, 2003) para os povos de língua carib, enfatizando a importância da sua articulação com o cotidiano.

${ }^{6}$ No ritual funerário toimai é o tipiti materno que encerra os ossos e as cinzas da jovem falecida.

${ }^{7}$ Trata-se do sapo cururu (Bufo marinus). Pële acumula atributos de guardiã do fogo e dos saberes culinários.

${ }^{8}$ Sobre esta pretensa flexibilidade ainda não há estudos conclusivos na literatura sobre os Wayana.

${ }^{9}$ Segundo a formulação de Menget (1985:136) para a região do Alto Xingu.

${ }^{10} \mathrm{O}$ termo genérico para sobrenatural é ipó; estão subdivididos nos ipótunawaré (aquáticos) e nos ipóiturtaré (terrestres).

${ }^{11} \mathrm{O}$ mito foi analisado a partir de dados colhidos em pesquisa de campo e cotejados com as versões apresentadas por E. Maganã (1987) e D. Schoepf (1987). Este autor o designa como "A narrativa da criação" e também como a "História dos deuses kuyuli". As versões de Maganã compõem-se na realidade de três fragmentos, referidos como "A obtenção do fogo".

${ }^{12}$ Para uma discussão sobre este termo, consultar Schoepf (1987) e Lopes (1994). 
${ }^{13}$ Uma bebida fermentada, especialmente apreciada, cuja base é o beiju mole, feito de mandioca.

${ }^{14}$ Aruma é arumã em língua aparai. Consultar Camargo \& Rivière (2001/2002) para uma discussão sobre a incorporação de termos aparai num falar wayana de construção arcaica.

${ }^{15}$ Segundo os especialistas wayana, a trama cerrada de fios de algodão é específica de uma placa dorsal, wariptá, de uso ritual (Velthem 2003:205). Este objeto não foi observado em campo, mas um exemplar do século XIX encontra-se no Musée du Quai Branly, em Paris.

${ }^{16}$ O urucu (Bixa orellana) é designado pelos Wayana de onot. É cultivado em roças e aldeias e de suas sementes é produzida uma tintura de cor vermelha, após longo processamento.

${ }^{17}$ Este mesmo termo designa os tecidos industriais, estampados e também as letras do alfabeto, as palavras escritas ou impressas, constituindo a "pintura corporal" dos livros (Velthem 1998, 2003).

${ }^{18}$ A respeito da corporalidade dos artefatos, ver Velthem (2003) e Lagrou (2007).

${ }^{19}$ Ipokan é o vocábulo empregado pelos Wayana para designar tudo o que lhes é próprio e apropriado e assim seria aplicável a todos os elementos da vida indígena. De modo específico, ipokan nomeia a música, o canto, o idioma e a tradição oral e a vida social e afetiva com os parentes consanguíneos. 


\section{Referências bibliográficas}

CAMARGO, Eliane \& RIVIÈRE, Henri. 2001/2002. "Trois chants de guerre wayana". Amerindia. Langues de Guyane, 26/27:87-122.

CARNEIRO, Robert. 2000. "The evolution of the tipiti. A study in the process of invention". In: G. Feinman \& L. Manzanilla (eds.), Cultural evolution: contemporary viewpoints. Kluwer Academia Plenum Publishers. pp. 61-93.

CHAUMEIL, Jean-Pierre. 2005. “Un 'método de assimilación'. Sobre la noción de transformacion en unas culturas sudamericanas". In: J. F. Buchard \& J. P Chaumeil (eds.), Chamanismo y sacrificio. Bogotá: Editions de l'IFEA e FIAN. pp. 165-176.

GALlOIS, Dominique. 1986. Migração, guerra e comércio. Os Waiãpi na Guiana. São Paulo: FFLCH/USP (Antropologia, 15).

. 2005. "Introdução: Percursos de uma pesquisa temática". In: - (org.), Redes de relação nas Guianas. São Paulo: Associação Editorial Humanitas: Fapesp. pp. 7-22.

GOMBRICH, Ernst. 1999. "Meditações sobre um cavalinho de pau ou as raízes da forma artística". In: Meditações sobre um cavalinho de pau e outros ensaios sobre a teoria da arte. São Paulo: EDUSP. pp. 1-11.

GOW, Peter. 1988. "Visual compulsion: design and image in Western Amazonian cultures". Revindi. Revista Indigenista Latinoamericana, 2:19-32. . 1999a. "Piro designs: painting as meaningful action in an Amazonian lived world". Journal of the Royal Anthropological Institute (N.S.), 5:229-246. . 1999b. "A geometria do corpo". In: A. Novaes (org.). A outra margem do
Ocidente. São Paulo: Cia das Letras. pp. 299- 315.

GUSS, David. 1990. To weave and sing. Art, symbol, and narrative in the South American rainforest. Berkeley: Berkeley: University of California Press.

LAGROU, Elsje. 2007. A fluidez da forma: arte, alteridade e agência em uma sociedade amazônica (Kaxinawa, Acre). Rio de Janeiro: Topbooks Editora.

LOPES, Paula M. D. 1994. O pluralismo médico Wayana-Aparai: uma experiência intercultural. Tese de Doutorado, FFLCH, Universidade de São Paulo.

MAGAÑA, Edmundo. 1987. Contribuiciones al estudio de la mitologia y astronomia de los indios de la Guayana. (CEDLA 35) Dordrecht: ICG Printing.

MENGET, Patrick. 1985. "Jalons pour une étude comparative (Guerre, societés et vision du monde dans les basses terres de l'Amérique du Sud)". Journal de la Société des Americanistes, LXXI:129-141.

MUNN, Nancy. 1973. Walbiri iconography. Graphic representation and cultural symbolism in a central autralian society. London: Oxford University Press.

OVERING, Joanna. 1991. "A estética da produção: o senso de comunidade entre os Cubeo e os Piaroa". Revista de Antropologia, 34:7-34. . 1999. "Elogio do cotidiano: a confiança e a arte da vida social em uma comunidade amazônica". Mana. Estudos de Antropologia Cultural, 5(1):81-107. . 2006. "O fétido odor da morte e os aromas da vida. Poética dos saberes e processo sensorial entre os Piaroa da Bacia do Orenoco". Revista de Antropologia, 49(1):19-54. 
PIERCE, Charles. 1977. Semiótica. São Paulo: Perspectiva.

SCHOEPF, Daniel. 1987. "Le récit de la création chez les Wayana-Aparai du Brasil". Bulletin du Musée D'Ethnographie de Genève, 29:113138.

STADEN, Hans. 2008. Duas viagens ao Brasil. Primeiros registros sobre o Brasil (tradução de Angel Bojadsen). Porto Alegre: L\&PM.

VELTHeM, Lucia H. van. 1992. "Das cobras e lagartas: a iconografia Wayana". In: L. Vidal (org.), Grafismo indígena: estudos de antropologia estética. São Paulo: Studio Nobel/ Editora da Universidade de São Paulo/ FAPESP. pp. 53-65.

- 1998. A pele de Tuluperê. Uma etnografia dos trançados wayana. Belém: Museu Paraense Emilio Goeldi. - 2000a. "Os primeiros tempos e os tempos atuais: artes e estéticas indígenas". In: N. Aguilar (org.), Catálogo: Artes Indígenas. São Paulo: Associação Brasil 500 Anos. pp. 58-91.

- 2000b. "Fazer, fazeres e o mais belo feito". In: J. P. de Brito (ed.). Os índios, nós. Lisboa: Museu Nacional de Etnologia. pp. 174-179.

- 2003. O belo é a fera: a estética da produção e da predação entre os Wayana. Lisboa: Mus. Nac. de Etnologia/Assírio e Alvim. 


\section{Resumo}

Os índios Wayana, que vivem às margens do rio Paru de Leste, norte do estado do Pará, concebem que a fabricação de pessoas, casas, artefatos, padrões e muitas outras coisas está estreitamente relacionada aos demiurgos, porque eles as criaram nos tempos primordiais segundo uma tecnologia própria. Como enfatizam, os Wayana julgam-se apenas os "experimentadores" desses princípios criativos. Eles os empregam na elaboração de artefatos para uso cotidiano ou ritual, categorias estas que possuem características diferenciadas, resultado do poder generativo da tecnologia demiúrgica, mas que precisam ser controladas através das habilidades humanas. O artigo descreve os princípios criativos e de fabricação material em sua conectividade com as narrativas míticas e a cosmologia, detalhando os mecanismos das experiências realizadas pelos Wayana na produção e na utilização de obras belas e eficazes, objetivo de toda e qualquer criação.

Palavras-chave Amazônia, índios Wayana e Aparai, Cosmologia, Estética, Tecnologias, Cestaria

\section{Abstract}

The Wayana Amerindians, who inhabit the banks of the Paru de Leste river in the north of the state of Pará, conceive of the fabrication of persons, houses, artefacts, patterns, and many other things, as strictly related to the demiurges, since it was the latter who created them in primordial times according to their own technology. As the Wayana stress, they are merely the "experimenters" of these creative principles, which are employed in the elaboration of artefacts for daily or ritual use - these categories possesing differential characteristics as a result of the generative power of the demiurges' technology, but which need to be controlled through human abilities. The article describes creative principles and material fabrication in connection to mythical narratives and cosmology, detailing the mechanisms of the experiments carried out by the Wayana in the production and utilization of beautiful and effective works, which is the aim of every creative process.

Key words Amazonia, Wayana and Aparai Indians, Cosmology, Aesthetics, Technologies, Basketry 